\title{
Transoral endoscopic ultrasound-guided fine-needle biopsy of a tumor of the parapharyngeal space
}

The parapharyngeal space is a pyramidshaped space located between the base of the skull and the hyoid bone, lateral to the naso-oropharynx and medial to the jaw $[1,2]$. It contains the deep lobe of the parotid gland, cranial nerves IX-XII, the internal jugular vein, and the carotid artery [1]. A variety of benign and malignant tumors arise in the parapharyngeal space, the most common being of salivary gland and neurogenic origin [1]. Because of its deep location and concerns about damaging adjacent structures, the parapharyngeal space is difficult to access for biopsy [1-3]. Percutaneous, transoral, or transnasal approaches have been used; however, sampling may be challenging even under imaging guidance [2-5]. Here we report for the first time a technique of transoral biopsy using a flexible gastrointestinal echoendoscope.

A 41-year-old man with a remote history of mucoepidermoid carcinoma of the left parotid gland presented with a tumor of the right parapharyngeal space (•Fig.1). A multidisciplinary tumor board recommended biopsy; however, this was deemed difficult due to the tumor location. After discussion with a gastroenterologist experienced in endoscopic ultrasound (EUS), a decision was made for biopsy under EUS guidance.

With the patient in the left lateral position and under intravenous sedation, a flexible echoendoscope (Olympus GFUCT180) was introduced in a standard manner into the oral cavity and torqued clockwise. After passing the palatopharyngeal fold, the EUS transducer was gently wedged against the right lateral wall of the pharynx ( $\mathbf{F i g . 2}$ ). In this position the tumor was easily identified on the EUS image. Three passes with a 22-gauge Acquire needle (Boston Scientific) were performed ( Fig.3, $>$ Video 1). The specimen was processed for histological evaluation, which revealed pleomorphic adenoma ( $\mathbf{F i g . 4 )}$. The patient was dis-
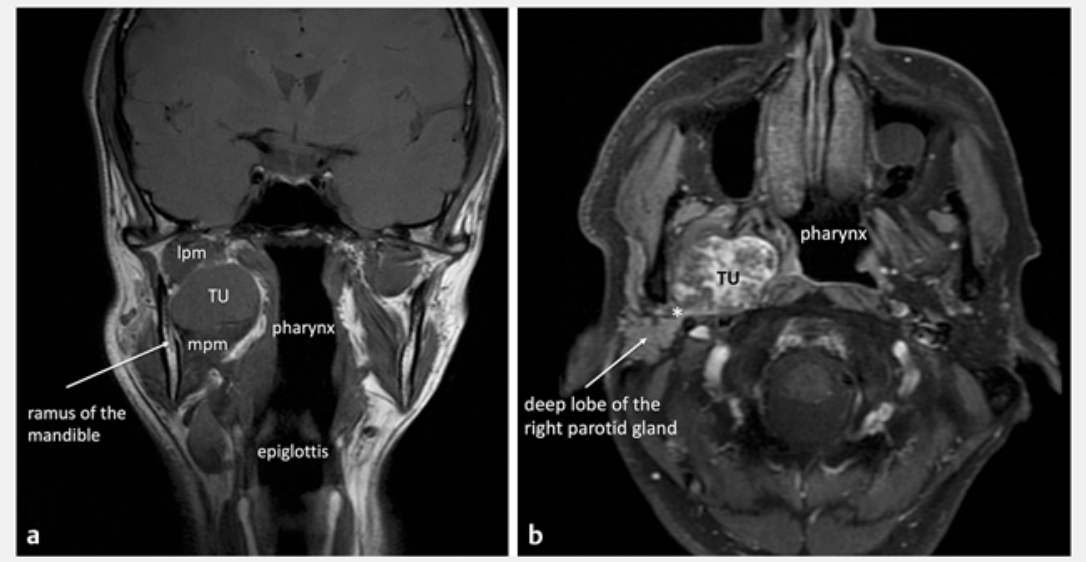

- Fig. 1 Magnetic resonance images showing a tumor (TU) of the right parapharyngeal space. a Unenhanced T1-weighted coronal image. The tumor is located between the wall of the nasopharynx, lateral (Ipm) and medial pterygoid muscles ( $\mathrm{mpm})$, and ramus of the mandible. It is $34 \mathrm{~mm} \times 25 \mathrm{~mm}$ in size, has well-delineated borders, and a homogeneous low-intensity T1 signal. b Gadolinium-enhanced transverse image. The tumor has an inhomogeneous enhancement pattern. A connection to the deep lobe of the right parotid gland is visible (asterisk).

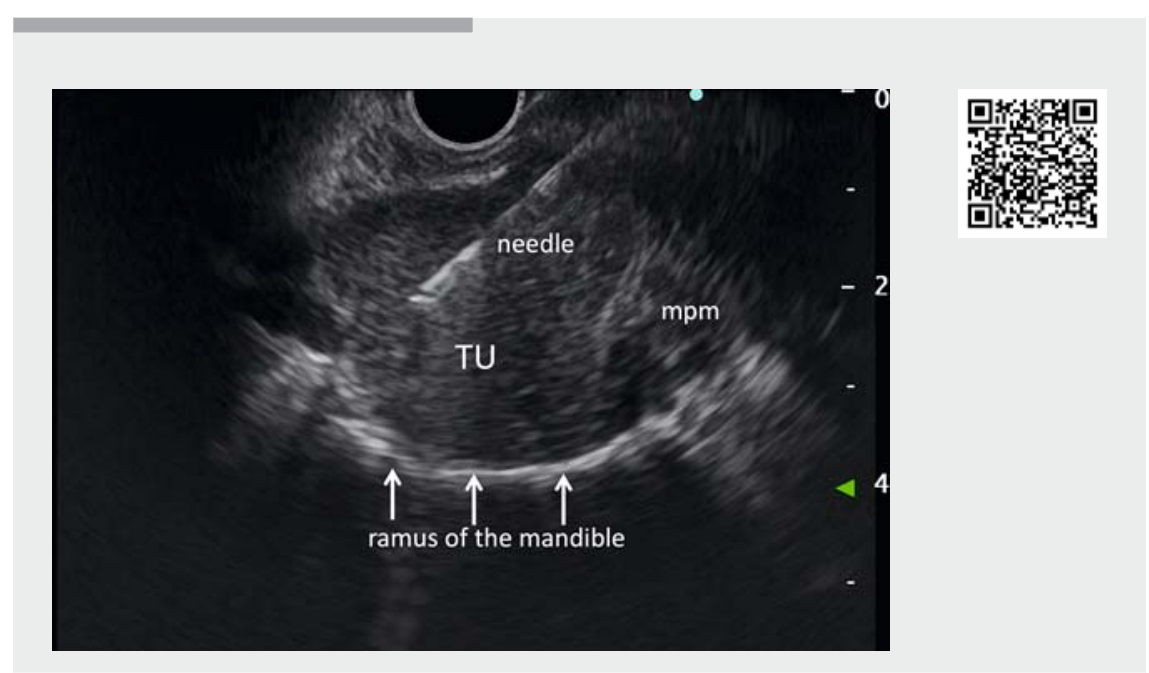

Video 1 Successful transoral endoscopic ultrasound-guided biopsy of a tumor of the parapharyngeal space (pleomorphic adenoma of the deep lobe of the parotid gland).

charged $48 \mathrm{~h}$ later after an uneventful course. The tumor was resected 4 weeks later. Surgical pathology confirmed the diagnosis of pleomorphic adenoma of the deep lobe of the right parotid gland.
Endoscopy_UCTN_Code_TTT_1AS_2AC 


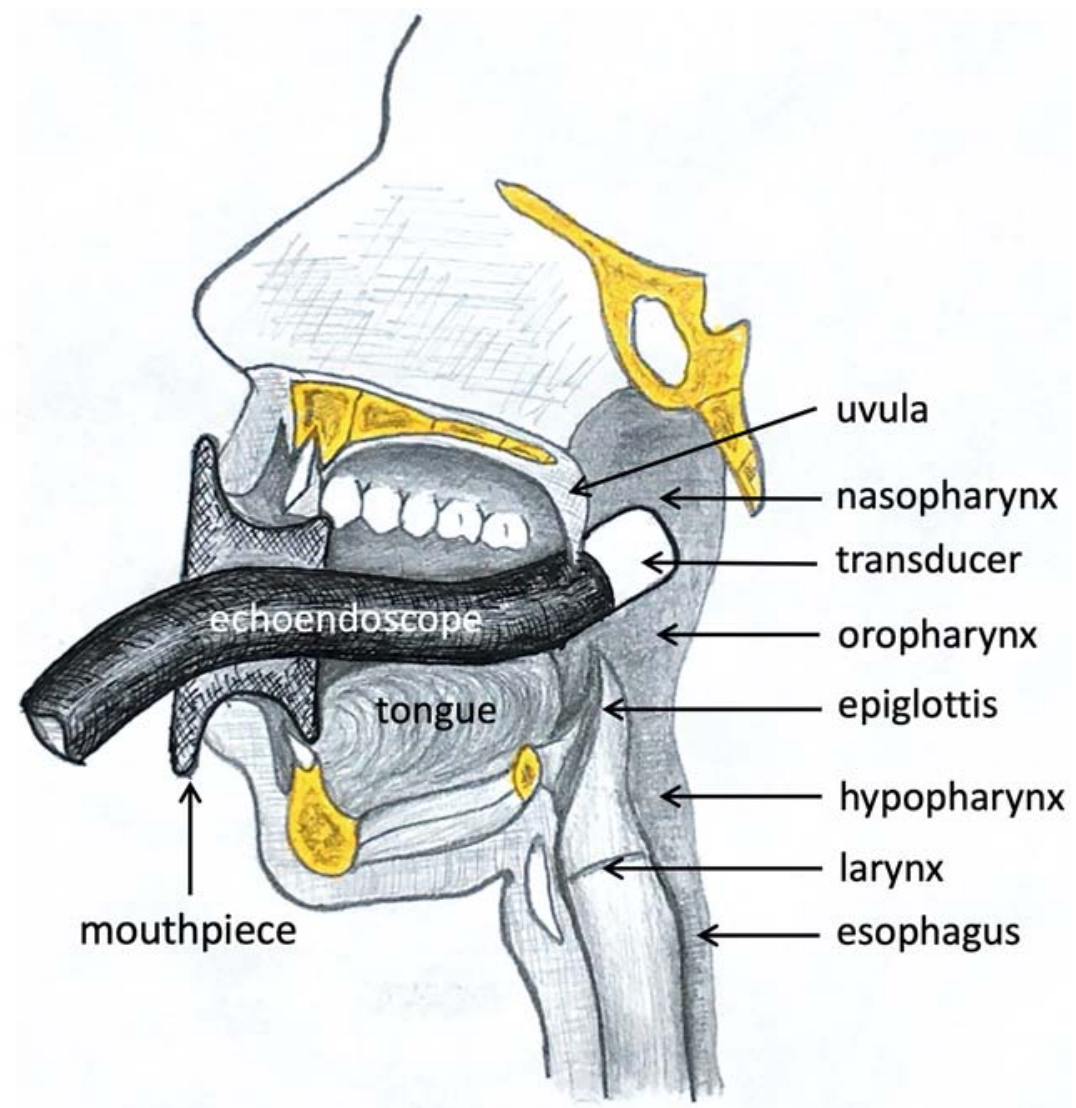

Fig. 2 Schematic drawing of the anatomy of the mouth and throat (midsagittal plane), showing the position of the echoendoscope during endoscopic ultrasound (EUS) examination and fine-needle biopsy of the tumor.

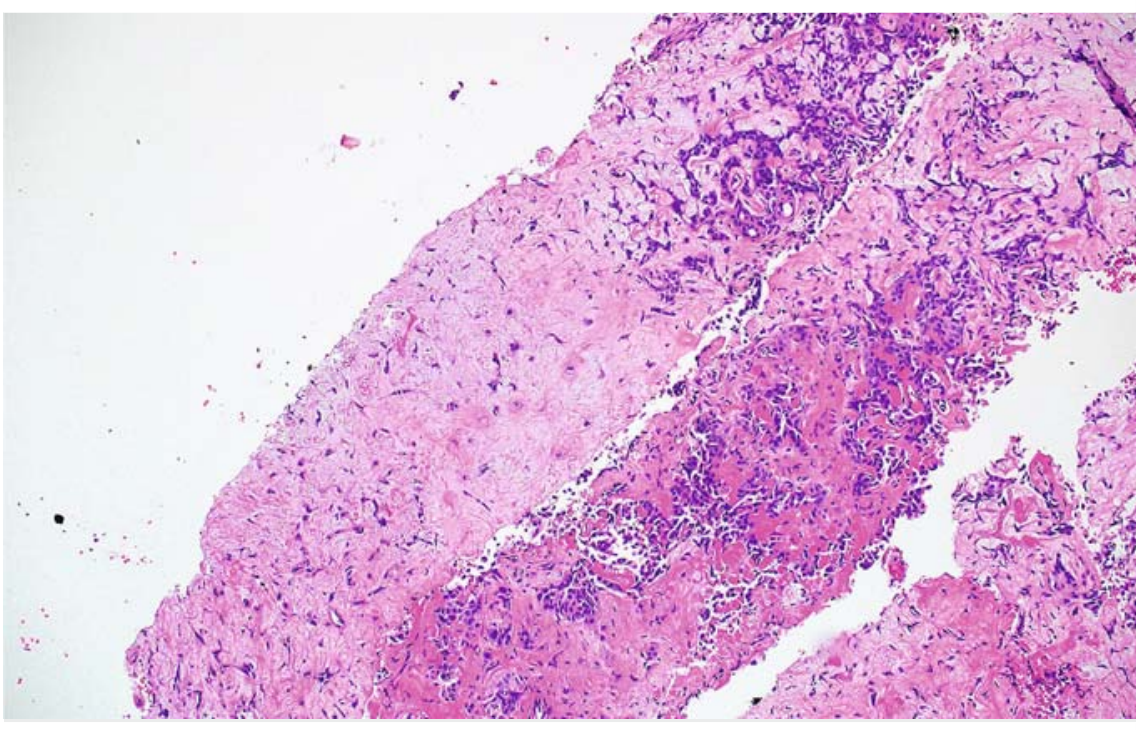

- Fig. 4 Specimen obtained by EUS-guided fine-needle biopsy under $100 \times$ magnification. Typical appearance of a pleomorphic adenoma of the parotid gland with epithelial, myoepithelial, and stromal components. Hematoxylin and eosin stain.

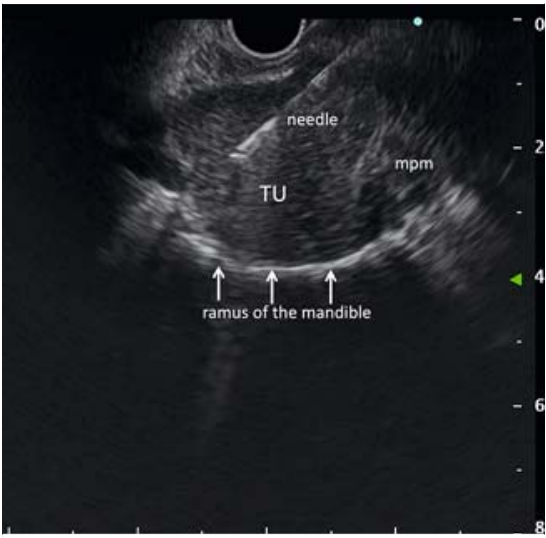

- Fig. 3 EUS image of a tumor of the right parapharyngeal space located between the pharyngeal wall, the medial pterygoid muscle ( $\mathrm{mpm})$, and the ramus of the mandible. The tumor (TU) is $34 \mathrm{~mm} \times$ $28 \mathrm{~mm}$ in size, has well-delineated borders and a hypoechoic, homogeneous echo pattern. A needle passing through the pharyngeal wall into the tumor is visible.

\section{Competing interests}

The authors declare that they have no conflict of interest.

\section{The authors}

Marcin Polkowski ${ }^{1,2}$, Jacek Lenartowicz ${ }^{3}$, Jakub Zwoliński ${ }^{3}$, Jakub Pałucki ${ }^{4}$, Andrzej Mróz $^{5,6}$, Kamil Sokół ${ }^{6}$, Jarosław Reguła ${ }^{1,2}$

1 Department of Gastroenterological Oncology, Maria Skłodowska-Curie National Research Institute of Oncology, Warsaw, Poland

2 Department of Gastroenterology, Hepatology and Clinical Oncology, Center of Postgraduate Medical Education, Warsaw, Poland

3 Department of Head and Neck Cancer, Maria Skłodowska-Curie National Research Institute of Oncology, Warsaw, Poland

4 Department of Radiology, Maria Skłodowska-Curie National Research Institute of Oncology, Warsaw, Poland

5 Department of Pathology, Center of Postgraduate Medical Education, Warsaw, Poland

6 Department of Pathology and Laboratory Medicine, Maria Skłodowska-Curie National Research Institute of Oncology, Warsaw, Poland 
Corresponding author

\section{Marcin Polkowski, MD, PhD}

Department of Gastroenterological Oncology, Maria Skłodowska-Curie National Research Institute of Oncology, Roentgena 5, 02-781 Warsaw, Poland

mp.polkowski@gmail.com

\section{References}

[1] Lopez F, Suarez C, Vander Poorten V et al. Contemporary management of primary parapharyngeal space tumors. Head Neck 2019; 41: 522-535

[2] Riskalla A, Arora A, Vaz F et al. Novel use of ultrasound-guided endo-cavitary probe to evaluate an impalpable parapharyngeal mass. J Laryngol Otol 2010; 124: 328-329

[3] Abbas JR, Hamlett KEL, de Carpentier J. Image-guided transnasal endoscopic fine nee- dle aspiration or biopsy of parapharyngeal space tumours. J Laryngol Otol 2018; 132: 1026-1028

[4] Chen R, Cai Q, Liang F et al. Oral core-needle biopsy in the diagnosis of malignant parapharyngeal space tumors. Am J Otolaryngol 2019; 40: 233-235

[5] Arnason T, Hart RD, Taylor SM et al. Diagnostic accuracy and safety of fine-needle aspiration biopsy of the parapharyngeal space. Diagn Cytopathol 2012; 40: 118-123

\section{Bibliography}

Endoscopy 2021; 53: E145-E147

DOI 10.1055/a-1216-9928

ISSN 0013-726X

published online 5.8.2020

(c) 2020. Thieme. All rights reserved.

Georg Thieme Verlag KG, Rüdigerstraße 14,

70469 Stuttgart, Germany
ENDOSCOPY E-VIDEOS

https://eref.thieme.de/e-videos

口回 Endoscopy E-Videos is a free Fection, reporting 田: on interesting cases and new techniques in gastroenterological endoscopy. All papers include a high quality video and all contributions are freely accessible online.

This section has its own submission website at https://mc.manuscriptcentral.com/e-videos 